\title{
An Unusual Side Effect of Dabigatran Etexilate Use - Acute Renal Failure
}

\author{
(1) Ekim Sağlam Gürmen, (1) Adnan Bilge \\ Department of Emergency Medicine, Manisa Celal Bayar University Faculty of Medicine, Manisa, Turkey
}

\begin{abstract}
Dabigatran etexilate is a prodrug with anticoagulant effect through inhibition of thrombin. Although it does not require laboratory monitoring and has minimal food-drug interaction, its disadvantages are bleeding, common GIS-related side effects and the need for dosage adjustment according to the severity of liver/renal failure. We aimed to present and discuss an unusual side effect of dabigatran etexilate.
\end{abstract}

Keywords: New oral anticoagulant drugs, acute renal failure, creatinine clearance

\section{Introduction}

Anticoagulants are effective drugs in the prevention and treatment thromboembolic events. In recent years, novel oral anticoagulants (NOACS) such as dabigatran etexilate, rivaroxaban, apixaban, edoxaban have started to take part in treatment guidelines and daily clinical practice. These drugs do not require dosage monitoring, have minimal food-drug interactions and are at least as effective as warfarin (1-3). Dabigatran etexilate is an oral prodrug that is converted to its fully active form by esterases, that reaches its peak plasma value at the $2^{\text {nd }}-3^{\text {rd }}$ hours, and that is a quite specific competitive direct thrombin inhibitor (1). It has a rapid effect (1-2 hours), short half-life (1217 hours) and it is mostly (80\%) excreted through kidneys. Since NOACs, particularly dabigatran etexilate, have varying rates of renal excretion, the renal functions of the patients should be routinely monitored when using the drug (2-4). NOACs are not recommended for patients with creatinine clearance below $30 \mathrm{ml} / \mathrm{min}$ and patients with prosthetic heart valves, and the drug requires a dose adjustment when the creatinine clearance is between $30-49 \mathrm{~mL} / \mathrm{min}$ (5). Ecarin clotting time, thrombin time and activated partial thromboplastin time (aPTT) are the tests used to evaluate the therapeutic effect of the drug, and these time periods are prolonged in patients using dabigatran etexilate. A normal aPTT level indicates that dabigatran etexilate has no clinically significant effect (6). The only Food and Drug Administration (FDA)-approved antidote for dabigatran etexilate is idarucizumab, a NOAC-specific antidote (7). In this study, we aimed to emphasize that monitoring the side effects and complications of dabigatran etexilate that does not require routine coagulation monitorization may be beneficial by using creatinine clearance $(\mathrm{CrCl})$, especially in elderly patients.

\section{Case Report}

A 75-year-old female patient presented to our emergency department with shortness of breath and poor general condition. The patient had a medical history of congestive heart failure, atrial fibrillation and hypertension, and she was on diltiazem, furosemide and sertraline. Recently, dabigatran etexilate (150 mg, twice daily) was added to these drugs. The patient stated that she had not urinated in the last three days. 
Her physical examination findings were as follows: GCS $=15$, blood pressure $=70 / 40 \mathrm{mmHg}$, pulse $=90$ beats $/ \mathrm{min}$, respiratory rate $=24 / \mathrm{min}, \mathrm{SO}_{2}=88 \%$, body temperature $=36.6{ }^{\circ} \mathrm{C}$, pretibial edema $=-/-$. The ECG revealed atrial fibrillation and bilateral effusion was observed in posterior-anterior chest X-ray. Urine flow was $20 \mathrm{cc} /$ hour. The laboratory results were as follows: $\mathrm{pH}=7.46, \mathrm{HCO}_{3}=25.6 \mathrm{mmol} / \mathrm{L}$, international normalized ratio $(I N R)=9.16$, aPTT=110.2 sec, $\mathrm{Hgb}=6.1 \mathrm{~g} / \mathrm{dL}, \mathrm{PLT}=390 \mathrm{10} / \mu \mathrm{L}$, creatinine $=4.51 \mathrm{mg} / \mathrm{dL}$, urea $=103 \mathrm{mg} / \mathrm{dL}, \mathrm{Na}=137 \mathrm{mEq} / \mathrm{L}$ and $\mathrm{K}=4.4 \mathrm{mEq} / \mathrm{L}$. The creatinine clearance was calculated as 9 $\mathrm{mL} / \mathrm{min}$. Inotropic support and 1 unit of fresh frozen plasma were administered. Since the patient had neither liver nor hematological disorder that would increase the INR value, it was assumed that NOAC created a false-positive increase in INR value. As the patient's previous creatinine level was $0.93 \mathrm{mg} / \mathrm{dL}$, urea level was $50.3 \mathrm{mg} / \mathrm{dL}$ and creatinine clearance was $61.16 \mathrm{~mL} / \mathrm{min}$ during her last follow-up, the new onset increased creatinine level was thought to be associated with dabigatran etexilate and dabigatran etexilate treatment was ceased. The patient was admitted to the intensive care unit of internal medicine department for monitoring. The follow-up examination revealed that urea level was $46.5 \mathrm{mg} / \mathrm{dL}$, creatinine level was $0.99 \mathrm{mg} / \mathrm{dL}$ and creatinine clearance was $56.31 \mathrm{~mL} / \mathrm{min}$. Subsequently, the patient was discharged with full recovery after eleven days of hospitalization with recommended follow-up control visits.

\section{Discussion}

NOACs are oral anticoagulants that have been in use in recent years with the purpose of prevention and treatment of thromboembolic events. These drugs are considered safe and effective since they have an FDA-approved antidote, they do not require dose monitoring and food-drug interaction is minimal $(2,3)$. However, gastrointestinal safety profiles and bleeding rates have not yet been entirely identified. There are two groups of NOACs for clinical application, namely oral direct thrombin inhibitors (dabigatran etexilate) and oral direct factor Xa inhibitors (rivaroxaban, apixaban, edoxaban).

The recommended dose for dabigatran etexilate is $150 \mathrm{mg}$ 2 times a day, according to the FDA and EMA regulations. The Turkish drug license of dabigatran etexilate indicates that it should not be used when creatinine clearance is below $30 \mathrm{~mL} /$ min, and this is listed among its contraindications (8). It has also been suggested that the dose should be reduced in cases of moderate renal failure ( $\mathrm{CrCl}: 30-50 \mathrm{~mL} / \mathrm{min})$. According to the RE-LY (Randomized Evaluation of Long-Term Anticoagulation Therapy) study, the most common side effects are dyspepsia and gastrointestinal hemorrhage, followed by dyspnea, coughing, dizziness, arthralgia, peripheral edema, and fatigue (9).

\section{Conclusion}

To conclude, acute renal failure has not been reported within the side effect profile of dabigatran etexilate, which has a high rate of renal excretion and its dosage is controlled by using the creatinine clearance level. Dabigatran etexilate does not require routine coagulation monitoring, and its dosage adjustment is not made according to coagulation tests. However, we believe that it may be useful to monitor dabigatran etexilate treatment through creatinine clearance, particularly in elderly patients.

\section{Ethics}

Informed Consent: The manuscript is merely a case report, and no research was performed necessitating obtaining an informed consent. Also, there was no need to apply to the Research Ethics Committee of the Medical Faculty. The case report has written in an anonymous characteristic, thus secret and detailed data about the patient has removed. Following discharge of the patient from our hospital, she has not presented for her followup control examinations. When we decided to present the patient as a case report, we were not able to get in touch for obtaining her consent. Therefore, we have not been able to present any patient consent for publication in your journal up to now.

Peer-review: Externally peer-reviewed.

\section{Authorship Contributions}

Surgical and Medical Practices: E.S.G., A.B., Concept: E.S.G., Design: E.S.G., Data Collection or Processing: E.S.G., Analysis or Interpretation: E.S.G., A.B., Literature Search: E.S.G., A.B. Writing: E.S.G.

Conflict of Interest: No conflict of interest was declared by the authors.

Financial Disclosure: The authors declared that this study received no financial support

\section{References}

1. Gnoth MJ, Buetehorn U, Muenster U, Schwarz T, Sandmann S. In vitro and in vivo P-glycoprotein transport characteristics of rivaroxaban. J Pharmacol Exp Ther. 2011;338:372-80.

2. Connolly SJ, Ezekowitz MD, Yusuf S, Eikelboom J, Oldgren J, Parekh A, et al Dabigatran versus warfarin in patients with atrial fibrillation. N Engl J Med. 2009;361:1139-51.

3. Camm AJ, Lip GY, De Caterina R, Savelieva I, Atar D, Hohnloser SH, et al. 2012 focused update of the ESC Guidelines for the management of atrial fibrillation: an update of the 2010 ESC Guidelines for the management of atrial fibrillation. Developed with the special contribution of the European Heart Rhythm Association. Eur Heart J. 2012;33:2719-47.

4. Granger CB, Alexander JH, McMurray JJ, Lopes RD, Hylek EM, Hanna M, et al Apixaban versus warfarin in patients with atrial fibrillation. N Engl J Med. 2011;365:981-92.

5. Heidbuchel H, Verhamme P, Alings M, Antz M, Hacke W, Oldgren J, et al. European Heart Rhythm Association pratical guide on the use of new ora 
anticoagulants in patients with non-valvular atrial fibrillation. Europace. 2013;15:625-51.

6. Liew A, Eikelboom JW, O'Donnell M, Hart RG. Assessment of anticoagulation intensity and management of bleeding with old and new oral anticoagulants. Can J Cardiol. 2013;29(7 Suppl):34-44.

7. Pollack CV Jr, Reilly PA, Eikelboom J, Glund S, Verhamme P, Bernstein RA, et al. Idarucizumab for Dabigatran reversal. N Engl J Med. 2015;373:511-20.
8. PRADAXAR $75 \mathrm{mg}$ sertkapsul. Boehringer Ingelheim illacTicaret A.Ş. RuhsatTarihi: 14.03 2011 KUB Tarihi: 13.05.2011 Available from:http: //www. iegm.gov.tr/Folders/KubKT/.

9. Kaiser C. Pradaxa Benefit Outweighs Bleeding Risk, FDA Says. Dec 7, 2011; Available from: http: //abcnews.go.com/Health/ HeartDiseaseNews/pradaxabenefit-outweighs bleedingriskfda/story?id=15106519\#.TuUOJdXiVHQ. 